\title{
ASTUDY OF CORRELATION BETWEEN CYTOLOGY AND HISTOPATHOLOGY WITH COLPOSCOPIC FINDINGS
}

Ramadevi E ${ }^{1}$, Mamata $\mathbf{N}^{* 1}$, Madhavi G $\mathbf{B}^{2}$, Sudha Rani $\mathbf{V}^{2}$, Padmalatha $\mathbf{R}^{3}$, Shamili G ${ }^{4}$.

${ }^{1}$ Professor and HOD, Department of OBG, Chalmeda Anand Rao Institute of Medical Sciences, Karimnagar, Telangana, India.

*2 Professor, Department of OBG, Chalmeda Anand Rao Institute of Medical Sciences, Karimnagar, Telangana, India.

${ }^{3}$ Associate Professor, Department of OBG, Chalmeda Anand Rao Institute of Medical Sciences, Karimnagar, Telangana, India.

${ }^{4}$ Post Graduate Student, Department of OBG, Chalmeda Anand Rao Institute of Medical Sciences, Karimnagar, Telangana, India.

\section{ABSTRACT}

Background and aim of the study: Cervical cancer is the second most frequent cancer worldwide. This study was carried out to study the correlation of pap smear, colposcopy and histopathology in women with unhealthy cervices. This prospective analytical study was carried out in department of obstetrics and gynecology in a CAIMS tertiary care hospital.

Materials and Methods: This was a prospective clinical study conducted in 100 women who fulfilled the selection criteria. Among women attending the OPD who fulfilled the selection criteria were randomly selected. 100 women were randomly selected from patients' attending the gynaecology OP. Pap smear, colposcopy and biopsy were done for all the cases after proper counseling. The result were tabulated and analysed.

Results: Majority $70.5 \%$ of CIN occurred in the age group of $30-49$ years, $41.1 \%$ with CIN were para $2,35.2 \%$ with $\mathrm{CIN}$ were para 3 and $17.6 \%$ were greater than para 4 showing high incidence of CIN in multiparity. The incidence of CIN was found to be high among the lower income group $88.2 \%$.

Conclusion: Overall though colposcopy is more sensitive with less false negative values and colpohistological is better, cytology is more and has features of being an ideal screening test- easy availability, low cost less training along with histopathological correlation

KEY WORDS: Cancer cervix, Colposcopy, CIN (cervical intraepithelial neoplasia).

Address for correspondence: Dr. Mamata N, MD(OBG), Professor, Department of Obstetrics and Gynaecology, Chalmeda Anand Rao Institute of Medical Sciences, Karimnagar-505001, Telangana, India.E-Mail: mamatha969@gmail.com

\begin{tabular}{|l|lc|}
\hline \multicolumn{3}{|c|}{ Online Access and Article Informtaion } \\
\hline Quick Response code & \multicolumn{1}{|c|}{ International Journal of Integrative Medical Sciences } \\
& \multicolumn{1}{c}{ www.imedsciences.com } \\
\cline { 2 - 3 } & Received: 31-05-2017 & Accepted: 01-06-2017 \\
Dol: 10.16965/ijims.2017.105 & Reviewed: 31-05-2017 & Published: 05-08-2017 \\
\hline Source of Funding: Self & \multicolumn{2}{c|}{ Conflicts of interest: None } \\
\hline
\end{tabular}

\section{BACKGROUND}

Cervix is the most frequent of all the genital tract cancers. It is a very common for the gynaecologists who work in a tertiary care institutes in the developing countries to get referrals from practitioners and peripheral health centres for patients with a clinical diagnosis of an "unhealthy cervix". Unhealthy cervix is a group of cervical lesions, mostly chronic, which include chronic cervicitis, cervical erosions, lacerations, 
polyps and leukoplakia. These lesions can harbour premalignant lesions even when pap smear is negative. Hence colposcopy might be of more use in detecting the premalignant lesions in these cases than just with pap smear alone.

Among women dying from malignant disease of all kinds, the cervix accounts for $5 \%$. Statistics vary from country to country and from race to race [1]. Carcinoma cervix is now recognized as preventable by cervical screening and curable especially if identified at an early stage $[2,3]$.

It best exemplifies the dictum "Prevention is Better than Cure". The easy accessibility of the cervix to inspection, palpation and application of cytological and tissue sampling procedures has led to extensive screening programs for early detection and treatment of the disease there by contributing to a remarkable lowering of Carcinoma of the incidence, and mortality from cervical cancer. The approach proposed for India and other developing countries without laboratory facilities and resources to envisage cytological screening of all adult women is called Down Staging [4].

According to Down Staging detection of the disease in an earlier stage when still curable, by nurses and the paramedical staff using a simple speculum for visual inspection of cervix. Visual screening is sub-optimal strategy in comparison to cytological screening. Exfoliative Cytology has assumed immense importance in screening for cervical cancer. It is simple, noninvasive, safe, outpatient procedure brings to light the hidden carcinoma or a precancerous condition by the exfoliated cells.

The key to treatment of abnormal cytology lies in accurate localization of the abnormal epithelium and this is only possible by colposcopy $[5,6]$. This technique can be performed quickly and easily in the outpatient department.

Cervical carcinoma can be detected by two methods i.e. cytology is Lab method of detection and colposcopy which is clinical method of detection and also histopathological examination of cytology smear. Each method deals with a different aspect of neoplasia. Cytology evaluates morphological changes in exfoliated cells, whereas colposcopy evaluates mainly the changes in the terminal vascular network of the cervix that reflect the biochemical and metabolic changes in the tissue. The colposcopically directed biopsy helps in diagnosing the presence of dysplastic changes and the extent of the same, so that the mode of management can be decided upon. In the present study abnormally appearance cervix were detected for carcinoma by cytology, colposcopy and colposcopically directed biopsy.

\section{MATERIALS AND METHODS}

The present study was conducted over a period of 2 years (2014-2016)on about 100m women who attended the Gynaecologicaloutpatient department at General Hospital. Women with abnormal appearance of cervix on inspection were evaluated by cytology, colposcopy and colposcopically directed biopsies and results are compared.

Inclusion Criteria: (i) Age group of women: $18-40$ years; (ii) Marital status: Married women only; (iii) Presenting symptoms included in the study were, (a) Leucorrhoea, (b) Backache, (c) Irregular menses, (d) Post coital bleeding; (iv) All women were examined in post menstrual period.

\section{Exclusion Criteria: (i) Pregnant women.}

Detailed history regarding age, age at marriage, sexual practices, religion, parity, age at first pregnancy, menstrual history, presenting symptoms was taken. A clinical examination was done; Pap smear was taken at the time of speculum examination. Colposcopy was done and in cases which required biopsy, colposcopically directed biopsy were taken. Staining was done with Universal stain for cytological preparations. Papanicolaou stain is Harri'shematoxylin is the optimum nuclear stain and combination of OG6 and EA 50 give the subtle range of green, blue and pink hues to the cell cytoplasm. Bethesda classification was used for reporting [4]. The colposcope on a rolling stand was used with a focal length of $300 \mathrm{~mm}$. It is a microscope which consists of the binocular head with eye pieces the main objective, the focusing mechanism, the microscope tilting mechanism, the illuminating system and built in filters. Green filter serves to enhance the fine 
detail of the vascular pattern of the target epithelium. The light source on the colposcope is halogen. Colposcopic signs was scored under the Reid Colposcopic index in the following categories [5]: (i) Sharpness of margin; (ii) Epithelial colour; (iii) Vascular pattern; (iv) lodine staining. Each category was given 3 points.

Scores Diagnosis $0-2 \mathrm{Hpv} / \mathrm{CIN} 1$

$$
\begin{array}{ll}
3-4 & \mathrm{CIN} 1 / \mathrm{CIN} 2 \\
5-8 & \mathrm{CIN} 2 / \mathrm{CIN} 3
\end{array}
$$

\section{RESULTS}

The results of the study are as follows. 100 women included in this study were all married belonging to age group 18-40 years.

Table 1: Demographic details.

\begin{tabular}{|c|c|c|c|c|c|}
\hline AGE (years) & $\begin{array}{c}\text { NO OF } \\
\text { CASES }\end{array}$ & $\begin{array}{c}\text { DYSPLASIA ON } \\
\text { CYTOLOGY }\end{array}$ & $\begin{array}{c}\text { ATYPICAL TZ ON } \\
\text { COLPOSCOPY }\end{array}$ & $\begin{array}{c}\text { HPE } \\
\text { DYSPLASIA }\end{array}$ & $\begin{array}{c}\text { MALIGNA } \\
\text { NCY }\end{array}$ \\
\hline$<18$ & 5 & - & - & & \\
\hline $19-29$ & 22 & 5 & 8 & 4 & \\
\hline 30 and above & 23 & 6 & 7 & 2 & 2 \\
\hline
\end{tabular}

Table 2: Classifications according to parity.

\begin{tabular}{|c|c|c|c|c|c|}
\hline PARIRTY & $\begin{array}{c}\text { NO OF } \\
\text { CASES }\end{array}$ & $\begin{array}{c}\text { DYSPALSIA ON } \\
\text { CYTOLOGY }\end{array}$ & $\begin{array}{c}\text { ATYPICAL TZ ON } \\
\text { COLPOSCOPY }\end{array}$ & $\begin{array}{c}\text { HPE } \\
\text { DYSPLASIA }\end{array}$ & MALIGNANCY \\
\hline nulligravida & 5 & - & 1 & 1 & - \\
\hline $1-2$ & 20 & 6 & 5 & 4 & - \\
\hline $3-4$ & 17 & 3 & 4 & 1 & 2 \\
\hline 5 and above & 8 & 2 & 4 & - & - \\
\hline
\end{tabular}

Table 3: Classifications according to socioeconomic status.

\begin{tabular}{|c|c|c|c|c|c|}
\hline CLASS & $\begin{array}{c}\text { NO OF } \\
\text { CASES }\end{array}$ & $\begin{array}{c}\text { DYSPALSIA ON } \\
\text { CYTOLOGY }\end{array}$ & $\begin{array}{c}\text { ATYPICAL TZ ON } \\
\text { COLPOSCOPY }\end{array}$ & $\begin{array}{c}\text { HPE } \\
\text { DYSPLASIA }\end{array}$ & $\begin{array}{c}\text { MALIGN } \\
\text { ANCY }\end{array}$ \\
\hline I & Nil & - & - & - & - \\
\hline II & 4 & - & - & - & - \\
\hline III & 6 & - & 4 & 2 & - \\
\hline IV & 19 & 4 & 7 & 3 & 1 \\
\hline V & 21 & 7 & 4 & 1 & 1 \\
\hline
\end{tabular}

Table 4: Age at marriage.

\begin{tabular}{|c|c|c|c|c|c|}
\hline AGE & $\begin{array}{c}\text { NO OF } \\
\text { CASES }\end{array}$ & $\begin{array}{c}\text { DYSPALSIA ON } \\
\text { CYTOLOGY }\end{array}$ & $\begin{array}{c}\text { ATYPICAL TZ ON } \\
\text { COLPOSCOPY }\end{array}$ & $\begin{array}{c}\text { HPE } \\
\text { DYSPLASIA }\end{array}$ & $\begin{array}{c}\text { MALIGNA } \\
\text { NCY }\end{array}$ \\
\hline$<18$ & 5 & 1 & 3 & 2 & - \\
\hline $19-29$ & 22 & 5 & 8 & 3 & 2 \\
\hline$>30$ & 23 & 5 & 4 & 1 & - \\
\hline
\end{tabular}

Table 5: Presenting symptoms.

\begin{tabular}{|l|c|}
\hline \multicolumn{1}{|c|}{ SYMPTOMS } & NO OF CASES \\
\hline LEUCORRHEA & $23(46 \%)$ \\
\hline BACK ACHE & $4(8 \%)$ \\
\hline INTERMENSTRUAL BLEEDING & $5(10 \%)$ \\
\hline POST COITAL BLEEDING & $4(8 \%)$ \\
\hline LOSS OF WEIGHT & $5(10 \%)$ \\
\hline OTHERS & $9(18 \%)$ \\
\hline
\end{tabular}

Int J Intg Med Sci 2017;4(4):477-83. ISSN 2394 - 4137
Table 6: Cytology findings.

\begin{tabular}{|l|c|}
\hline \multicolumn{1}{|c|}{ OBSERVATION } & NO OF CASES \\
\hline Normal smear & $5(10 \%)$ \\
\hline Inflammatory & $25(50 \%)$ \\
\hline Dysplasia & $10(20 \%)$ \\
\hline Moderate dysplasia & $6(12 \%)$ \\
\hline Severe dysplasia & $4(8 \%)$ \\
\hline Invasive cancer & - \\
\hline
\end{tabular}

Table 7: Colposcopy findings in study.

\begin{tabular}{|l|c|}
\hline \multicolumn{1}{|c|}{ APPEARANCE } & NO OF CASES \\
\hline Normal & $8(16 \%)$ \\
\hline Erosion cervix & $14(28 \%)$ \\
\hline Inflammatory changes & $12(24 \%)$ \\
\hline Polyps & $1(2 \%)$ \\
\hline Leukoplakia & $1(2 \%)$ \\
\hline AW areas & $4(8 \%)$ \\
\hline Punctuate pattern & $4(8 \%)$ \\
\hline Mosaic patterns & $2(4 \%)$ \\
\hline Atypical vessels & - \\
\hline Unsatisfactory & $4(8 \%)$ \\
\hline
\end{tabular}

Table 8: Acetic acid applications.

\begin{tabular}{|l|c|}
\hline \multicolumn{1}{|c|}{ AW AREAS within TZ } & Total cases \\
\hline Flat AW areas with sharp margins & 16 \\
\hline $\begin{array}{l}\text { Dense opaque AW areas with sharp } \\
\text { margins with punctuate/mosaic pattern }\end{array}$ & 10 \\
\hline Total & 26 \\
\hline
\end{tabular}

Table 9: HPE Findings.

\begin{tabular}{|l|c|}
\hline \multicolumn{1}{|c|}{ HPE } & NO OF CASES \\
\hline Chronic cervicitits & $23(46 \%)$ \\
\hline Chronic cervicitits +erosion & $14(28 \%)$ \\
\hline Erosion cervix & $1(2 \%)$ \\
\hline Epithelial hyperplasia & $1(2 \%)$ \\
\hline Polyp & $2(4 \%)$ \\
\hline Mild dysplasia & $4(8 \%)$ \\
\hline Moderate dysplasia & $3(6 \%)$ \\
\hline Severe dysplasia & $2(4 \%)$ \\
\hline
\end{tabular}

Table 10: Correlation of pap smear and colposcopy directed biopsy.

\begin{tabular}{|c|c|c|c|c|c|c|c|c|}
\hline Test & $\begin{array}{c}\text { True } \\
\text { positive }\end{array}$ & $\begin{array}{c}\text { False } \\
\text { positive }\end{array}$ & $\begin{array}{c}\text { True } \\
\text { negative }\end{array}$ & $\begin{array}{c}\text { False } \\
\text { negative }\end{array}$ & $\begin{array}{c}\text { Sensiti } \\
\text { vity }\end{array}$ & specific & PPV & NPV \\
\hline ity & & & \\
\hline Pap smear & 3 & 5 & 36 & 6 & 29.4 & 87.9 & 33.3 & 85 \\
\hline
\end{tabular}

This study was a prospective study conducted in the dept. of obstetrics and gynaecology in 50 women who fulfilled the inclusion criteria.50 women were randomly selected from patients attending the gynaecology OPD, colposcopy, pap 
smear and biopsy were done for all the cases after proper counseling. The result were tabulated and analysed. To summarise- Majority $70.5 \%$ i.e (6/13) of CIN occurred in the age group of 30-49years $41.1 \%$ (3/7) with CIN were para2,35.2\%(6/17) with CIN were para 3 and $17.6 \%(3 / 17)$ were greater than para 4 showing high incidence of CIN in multiparity.The incidence of $\mathrm{CIN}$ was found to be high among the lower income group $88.2 \%$ i.e (15/17) 65\% $(11 / 17)$ of women with CIN were found to be illiterate. $41.1 \%$ (7/17) of women were married for $11-20$ years and $30 \%(5 / 17)$ of women married for more than 20years had CIN Among the 9 women who took OCP, $12 \%(2 / 17)$ had CIN. Incidence of $\mathrm{CIN}$ in the permanently sterilized group 59\%(10/17) and among IUCD user was 5.9\%(1/17) Among women who were diagnosed to have CIN 70.5\% (12/17) complained of excessive vaginal discharge $11.7 \%(2 / 17)$ of women had post coital bleeding. 59\% (10/17) women among the study group had erosion cervix on speculum examination.

Pap smear had sensitivity of $29 \%$ and specificity of $88 \%$ which was attributed to the high number of false negative smears PPV \& NPV of pap smear was $78 \%$.

Colposcopy showed a sensitivity of $82 \%$ and specificity of $81 \%$ Sensitivity was more than pap smear but specificity was less than pap smear. PPV \&NPV of colposcopy were found to be $48 \%$ and $95 \%$ respectively.

Accuracy of colposcopy was found to be $82 \%$ which was comparatively more accurate thanPap smear (78\%). This accuracy was high grade lesions than the low grade lesions

\section{DISCUSSION}

Cervical cancer was the second most frequent cancer worldwide, in women after breast carcinoma. However invasive cancer of the cervix was consider to be a preventable condition as it associated with a long pre invasive stage $(\mathrm{CIN})$ making it amenable to screening and treatment. In the present study screening was done in 50 women with abnormal symptoms like excessive white discharge, post coital bleeding, post menopausal bleeding, etc.Women with unhealthy cervix and women with dysplastic smears with colposcopy and its result were correlated with pap smear and biopsy to determine the sensitivity \& specificity of these methods in detecting CIN. Regarding age distribution, high incidence of $\mathrm{CIN}$ was fond among the age group of $30-49$ yrs with mean age 41 years which was seen $19 \%$ of cases. Kushtagi and Fernands in their study showed the prevalence of CIN was higher in women over 30 yrs. Vaidya A1 showed in his study that $\mathrm{CIN}$ was more prevalent in the age group of $>35$ years. Shaliniet al2 showed the mean age patients with cancer cervix was 35 vs 32 in patients with benign pathology in cervix.

Regarding parity, our study showed, increased incidence of CIN among multiparous women. $20.5 \%$ were para $2,15.7 \%$ were para 3 and 15 $\%$ were para 4 or more. Similar study by Shalini et al [11] showed the mean parity was 4.2 , in patients with invasive cancer Kushtagi and Fernandez showed the prevalence of CIN was significantly higher in parity of more than 2 . Vaidya et al [10] showed more positive cases of CIN were found with parity more than 4.This might be attributed tohormonal and nutritionalchanges OCP users, almost 11\% (2/ 9) showed features of CIN.

Out of $17 \%$ of IUCD user, the incidence of CIN was $5 \%(1 / 7)$. Out of $39 \%$ of women who had undergone sterilization permanently the incidence of CIN was 59\% (10/39) Prospective studies by Stern et al [13] in Los Angeles suggested an increased risk of progression of cervical dysplasia among the users of hormonal contraceptive. Vaidya et al [10] in their study showed $40 \%$ of risk of CIN 1 in women who had depot Provera injection.

According to Duggan [14] OCP produced progression to $\mathrm{CIN}$ by regulating oncogenic sequence of HPV. Among the complaints, majority of women (56\%) complained of excessive white discharge per vaginum. Among them CIN was found in 21.4\% (12/56) Excessive vaginal discharge playing a role in contributing to development of CIN was also proved to be a risk factor in the study conducted by Vaidya et al [10]. In their study, 24\% had vaginal discharge. Post coital bleeding was found in $7 \%(7 / 100)$ of cases. Among them CIN was found in $28.6 \%$ (2/ 7) Shalini $R$ et al [11], in their study showed the relationship of post coital bleeding and CIN. In 
their study, among the women who had post coital bleeding, $85.5 \%$ had benign findings, $5.6 \%$ had HPV and CIN 1, 3.6 had CIN 2 and 3 and $55 \%$ had invasive cancer.

There was no correlation between the duration of bleeding and pathology. Among those with intermenstrual bleeding, $9.09 \%$ (1 out of 11) had CIN. Among those with post menopausal bleeding $40 \%(2 / 5)$ had CIN. Regarding the clinical appearances of cervix, the most common finding was erosion cervix where the squamous epithelium of ectocervix was replaced by the columnar epithelium of endocervix. Erosion was seen in 59\% (59/100), rest of patients showed congestion in $16 \%$ Hypertrophy with congestion seen in 6\% Hypertrophy with erosion was seen in $12 \%$ and polyp was found in $5 \%$ of cases. CIN was found in $16.9 \%(2 / 16)$ in women who showed congestion, $12.5 \%(10 / 59)$ in women who showed erosion and $33.3 \%$ in women with hypertrophy with congestion \& $25 \%$ in women with hypertrophy + erosion. $5 \%$ acetic acid application produces suspicious areas in $29 \%$ (29/100) cases.

Among them, AW areas without any vascular pattern were found in $17.5 \%$, punctate pattern was seen in $4 \%$ and $2 \%$ showed mosaic pattern. Among those with AW areas $35.2 \%$ (6/17) were found to be CIN positive. Among those with dense opaque AW areas, 91\% (11/12) had CIN. Londhe $M$, Seshadri in their study showed VIAM had a sensitivity of $72.4 \%$ and a specificity of $54 \%$ and a false negative rate of $15.2 \%$. Lugo's iodine application produced iodine positivity in $24 \%$. Among them none had CIN. CIN was found in $29.4 \%(5 / 17)$ in partial iodine positivity and $70.5 \%(12 / 17)$ in iodine negativity.

Pap smear was taken for all cases. It showed mild dysplasia in $10 \%$ moderate dysplasia in $3 \%$ and severe dysplasia in $29.4 \%$. Pap smear correctly estimated $\mathrm{CIN}$ in $78 \%$ and undere stimated in $10 \%$ and overestimated in $12 \%$ (false positivity) Sensitivity of Pap smear was found to be very low- $29 \%$ compared to its specificity which was $88 \%$. This was attribution to the high number of false negative smears. that occur in pregnancy, immune suppression during pregnancy, and cervical trauma during vaginal delivery (Becker et al and Adadevoh et al ) Socio economic status had always been playing an epidemiological role in genesis of dysplasia. In our study, the incidence of CIN was found to be higher among the low income group (19.5\%) Vaidya et al [10] had showed that low socioeconomic status had a definite role on the development of dyskaryosis. In his study $80 \%$ of CIN I and $50 \%$ of CIN II were from the low income group. Poor personal hygiene poor living conditions, unstable marriages and early age at first intercourse are factors associated with both low socio economic conditions and cervical cancer.

Regarding the literacy CIN was more prevalent among the illiterates. In our study, $61 \%$ (11 out of 32) of CIN was found among the illiterates. This was attributed to lack of awareness of symptoms and failure to seek medical care. Duration of marriage and duration of exposure to sexual intercourse had a distinct role in genesis of cervical dysplasia. In our study, the incidence of $\mathrm{CIN}$ was $22 \%$ in women who were married for $11-20$ yrs and $25 \%$ among women who were married for $>20$ years. Kushtagi et al had demonstrated the severity or underlying CIN increased with increase in the duration of marital life and hence the increase in the duration of sexual intercourse.

Increasing number of sexual partners had the effect on increasing the risk of developing CIN and invasive disease. Sex with high risk males was also another risk factor for the development of CIN. The relationship between oral contraceptives \& development of $\mathrm{CIN}$ had been investigated by IARC-international agency for Research in Cancer and they concluded that the use of OCP increased the risk of CIN upto 4 fold after 5 or more years among the HPV DNA Positive women.

In our study we found that none of the women who practices barrier contraception had CIN. Among the $9 \%$ of OCP users, almost 11\% (2/9) showed features of CIN. Out of $17 \%$ of IUCD user, the incidence of CIN was $5 \%(1 / 7)$. Out of $39 \%$ of women who had undergone sterilization permanently the incidence of CIN was 59\% (10/ 39) Prospective studies by Stern et al [13] in Los Angeles suggested an increased risk of progression of cervical dysplasia among the users of hormonal contraceptive. Vaidyaet al [10] in their study showed $40 \%$ of risk of CIN 1 
in women who had depot Provera injection. According to Duggan [14] OCP produced progression to $\mathrm{CIN}$ by regulating oncogenic sequence of HPV.

Among the complaints, majority of women (56\%) complained of excessive white discharge per vaginum. Among them CIN was found in $21.4 \%$ (12/56) Excessive vaginal discharge playing a role in contributing to development of CIN was also proved to be a risk factor in the study conducted by Vaidya et al [10]. In their study, $24 \%$ had vaginal discharge. Post coital bleeding was found in $7 \%$ (7/100) of cases. Among them CIN was found in $28.6 \%$ (2/7) Shalini R et al [11], in their study showed the relationship of post coital bleeding and CIN. In their study, among the women who had post coital bleeding, 85.5 \% had benign findings, 5.6\% had HPV and CIN 1 , 3.6 had CIN 2 and 3 and $55 \%$ had invasive cancer. There was no correlation between the duration of bleeding and pathology. Among those with intermenstrual bleeding, $9.09 \%$ (1 out of 11 ) had CIN. Among those with post menopausal bleeding $40 \%(2 / 5)$ had CIN. Regarding the clinical appearances of cervix, the most common finding was erosion cervix where the squamous epithelium of ectocervix was replaced by the columnar epithelium of endocervix. Erosion was seen in 59\% (59/100), rest of patients showed congestion in $16 \%$ Hypertrophy with congestion seen in $6 \%$ Hypertrophy with erosion was seen in $12 \%$ and polyp was found in $5 \%$ of cases. CIN was found in $16.9 \%(2 / 16)$ in women who showed congestion, $12.5 \%(10 / 59)$ in women who showed erosion and $33.3 \%$ in women with hypertrophy with congestion \& $25 \%$ in women with hypertrophy + erosion. $5 \%$ acetic acid application produces suspicious areas in $29 \%$ (29/100) cases

Among them, AW areas without any vascular pattern were found in $17.5 \%$, punctate pattern was seen in $4 \%$ and $2 \%$ showed mosaic pattern. Among those with AW areas 35.2\% (6/17) were found to be CIN positive. Among those with dense opaque AW areas, 91\% (11/12) had CIN. Londhe M, Seshadri [6] in their study showed VIAM had a sensitivity of $72.4 \%$ and a specificity of $54 \%$ and a false negative rate of $15.2 \%$.

Lugo's iodine application produced iodine positivity in $24 \%$. Among them none had CIN.
CIN was found in $29.4 \%$ (5/17) in partial iodine positivity and $70.5 \%(12 / 17)$ in iodine negativity. Pap smear was taken for all cases. It showed mild dysplasia in $10 \%$ moderate dysplasia in $3 \%$ and severe dysplasia in $29.4 \%$. Pap smear correctly estimated $\mathrm{CIN}$ in $78 \%$ and underestimated in $10 \%$ and overestimated in $12 \%$ (false positivity) Sensitivity of Pap smear was found to be very low-29\% compared to its specificity which was $88 \%$. This was attribution to the high number of false negative smears.

This data suggested that with colposcopy as a screening tool, the rate of false negative cytology could be significantly reduced. Colposcopy enhanced cervical screening particularly in women with otherwise negative smears. Correlation between cytology and HPE was poor as far as mild dysplasias were concerned. But the correlation was good for moderate and severe dysplastic lesions. Correlation between colposcopic findings and biopsy showed a good correlation for higher grade lesions (CIN II and CIN III). Sensitivity was found to be $83 \%$ and specificity was $81 \%$. This showed a high sensitivity and a low specificity when compared to Pap smear. Low specificity when compared to Pap smear was due to the high incidence of unsuspected AW epithelium which might be due to inflammation, immature metaplasia, and latent HPV infections. Out of 17 cases which showed AW areas without vascular pattern only 5 were confirmed by biopsy.

Colposcopy and biopsy were positive in 14 out of $17(82.4 \%)$ cases while pap smear and biopsy were positive in only 5 out of 17 (29.4\%) cases. This indicated the usefulness of colposcopy in diagnosing lesions missed by pap smear. Olaniyan et al. [10] did a meta analysis of eight longitudinal studies and compared the correlation of colposcopy impression with biopsy results. Colposcopy accuracy was found to be $89 \%$ which agreed exactly with histology in 61 $\%$ of cases.

In the present study, the accuracy of colposcopy impression was found to be $82 \%$, Massad et al [18] reported an accuracy of $80 \%$.

The main reason for false negativity of cytology was due to sampling errors, samples being inadequate and suboptimal for interpretation [10]. 


\section{CONCLUSION}

Majority of women belonged to $30-40$ years of age, $15 \%$ were grand multipara, $35 \%$ belonged to socio-economic class IV, 59\% were married below 19 years and 3/4th of cases presented with white discharge as their major symptom. Overall though colposcopy is more sensitive with less false negative values and colpohistological is better, cytology is more and has features of being an ideal screening test- easy availability, low cost less training along with histopathological correlation.

\section{ACKNOWLEDGEMENT}

I am very thankful to the patients for providing their consent and helping us to publish this study and also thankful to our chairman SRI CHALMEDA LAXMI NARASIMHA RAO garu and our Director SURYANARYANA REDDY for providing their constant support for reaching the present endeveaour

\section{REFERENCES}

[1]. Vizcaino AP, Moreno V, Bosch FX, Munoz N, BarrosDios XM, Borras J, et al. International trends in incidence of cervical cancer: II. Squamous-cell carcinoma. Int J Cancer 2000;86:429-35.

[2]. Peto J, Gilham C, Fletcher O, Matthews FE. The cervical cancer epidemic that screening has prevented in the UK. Lancet 2004;364:249-56.

[3]. Cohn DE, Herzog TJ. New Innovations in cervical cancer screening ClinObstetGynecol 2001;44:53849.

[4]. Dunn TS, Awad R, Batal H. Papnicolaou Screening in an urgent care setting. Am J ObstetGynecol 2005;192:1084-6.

[5]. Apgar BS, Brotzman GL, Spitzer M, Ignatavicius DD. Colposcopy - principles and practice: an integrated textbook and Atlas, 1st edi. Philadelphia: WB Saunders. 2002.

[6]. Semple D, Saha A, Maresh M. Colposcopy and treatment neoplasia: are national of cervical intraepithelial standards achievable? $\mathrm{Br} \mathrm{J}$ ObstetGynaecol 1999;106(4):351-5.
[7]. Algotar K, Nalawade A, Dhanawat DG. Balloon Mitral Valvuloplasty: Maternal and Foetal Outcome. Bombay Hospital Journal 2004;47:03.

[8]. Wills S, Azhagammai, Kanthamani PN. Histo-cytocolposcopic evaluation of 39 cases of postmenopausal bleeding. The Journal of Obstetrics and Gynaecology of India 1991;41:99-102.

[9]. Agrawal U, Kaur M, Kharakwal S. Role of cytology and colposcopically directed biopsies in various lesions of cervix. The Journal of Obstetrics and Gynaecology of India 1989;39:548.

[10]. Vaidya, Olaniyan OB. Validity of colposcopy in the diagnosis of early cervical neoplasia a review African Journal of Reproductive Health 2002,6: 59 $-69$.

[11]. Shalini. R, Amitha. S, Neera. M.A. How alarming is post coital bleeding-a cytologic, colposcopic and histological evaluation GynaecolObstet Invest .1998, 45(3):205-8.

[12]. Adadevoh S.W; Forufouh B.K; Clinical cancer. International Journal of Gynaecology and obstetrics; 1993; 43(1):63-4.

[13]. Stern E. Epidemiology of dysplasias, Obstetgynaecol survey 1969, 24:711-23.

[14]. Duggan et al, Natural history of CIN lesions, European J.Gynaecol onco1988,19(4) 338- 44.

[15]. Basu P.S, Shankaranarayanan.R, Mandal.R, Roy.C, Das.P. Visual inspection of cervix with acetic acid and cytology in the early detection of cervical neoplasia in Kolkatta-India. International Journal of Cancer 2005; Sept- Oct 13(6): 626 -632.

[16]. Pete I, Toth. V, Bosze. P. The Value of colposcopy in screening of cervical carcinoma. European Journal of Gynaecol Oncology 1998, 19(2):120-2.

[17]. Sukhpreet L Singh, Nayana A Dastur ,Murari S. Nanavatti; Comparison of colposcopy and pap smear : Sensitivity, specificity and predictive values BHJ,NO.4,vol 42,Oct 2000.

[18]. Massad.LS, Collins. 'Strength of correlation between colposcopic impression and biopsy. Journal of Gynaecol Oncol 2003, June 89(3): 424- 8.

[19]. Bhalerao A, Kulkarni S, Ghike S, Kawathalkar, Joshi S. Correlation of pap smear, colposcopy and histopathology in women with unhealthy cervix. J South Asian Feder Obst Gynae 2012; 4(2):97-98.

How to cite this article: Ramadevi E, Mamata N, Madhavi $G B$, Sudha Rani V, Padmalatha R, Shamili G. A STUDY OF CORRELATION BETWEEN CYTOLOGY AND HISTOPATHOLOGY WITH COLPOSCOPIC FINDINGS. Int J Intg Med Sci 2017;4(4):477-483. DOI: 10.16965/ ijims.2017.105 